\title{
Bi-directional four wave mixing in semiconductor amplifiers for mid-span spectral inversion: theory and experiment
}

Bischoff, Svend; Buxens, Alvaro A.; Poulsen, Henrik Nørskov; Clausen, Anders; Mørk, Jesper

Published in:

Proceedings of CLEO'99

Link to article, DOI:

10.1109/CLEO.1999.834101

Publication date:

1999

Document Version

Publisher's PDF, also known as Version of record

Link back to DTU Orbit

Citation (APA):

Bischoff, S., Buxens, A. A., Poulsen, H. N., Clausen, A., \& Mørk, J. (1999). Bi-directional four wave mixing in semiconductor amplifiers for mid-span spectral inversion: theory and experiment. In Proceedings of CLEO'99 (pp. CTuW3). IEEE. https://doi.org/10.1109/CLEO.1999.834101

\section{General rights}

Copyright and moral rights for the publications made accessible in the public portal are retained by the authors and/or other copyright owners and it is a condition of accessing publications that users recognise and abide by the legal requirements associated with these rights.

- Users may download and print one copy of any publication from the public portal for the purpose of private study or research.

- You may not further distribute the material or use it for any profit-making activity or commercial gain

- You may freely distribute the URL identifying the publication in the public portal 


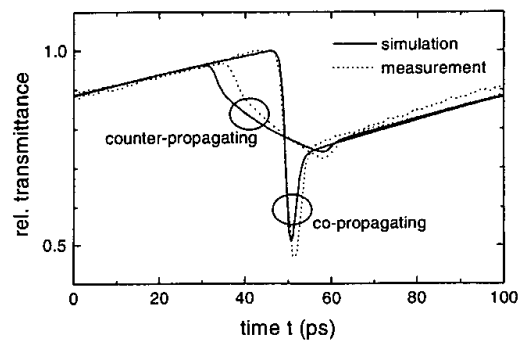

CTuW2 Fig. 1. Numerical simulation and experimental measurement of SOA gain dynamics for co- and counter-propagating pump-probe arrangements.

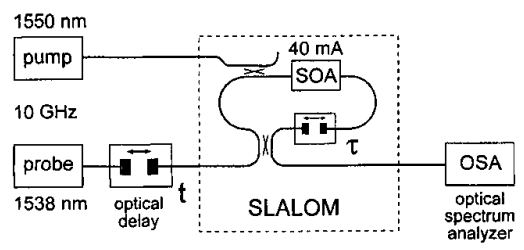

CTuW2 Fig. 2. Setup for SLALOM measurements. Two external cavity mode-locked lasers were used as sources for pump and probe (repetition rate $10 \mathrm{GHz}$, temporal width 2.0 ps FWHM as determined by autocorrelation measurements). The SOA was an InGaAsP-bulk SOA with a length of $980 \mu \mathrm{m}$.

LOM by varying the external optical delay $t$. Figure 3 shows modeling and experimental results for different asymmetries $\tau$ in the loop. In this particular case, $\tau$ was negative, which means that the counter-propagating pulses (traveling clockwise in the loop) arrive at the SOA before the co-propagating (counterclockwise) ones. It can be seen that the numerical results qualitatively describe the experimental behavior very well. The slight amplitude offset in the measurements originates most likely from the experimental conditions, including a

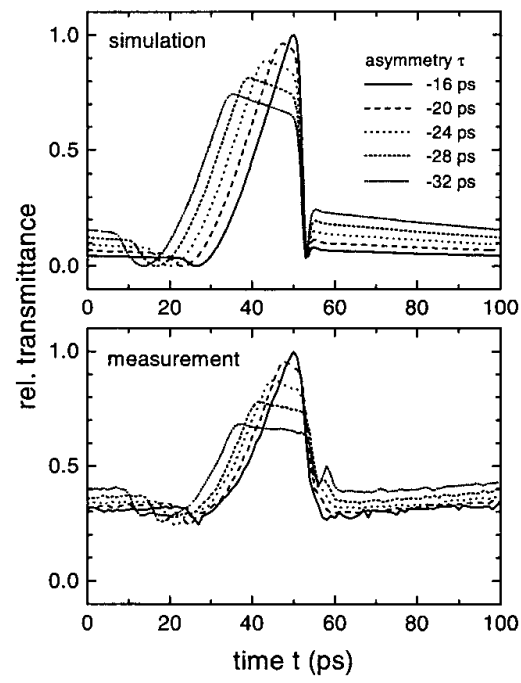

CTuW2 Fig. 3. Numerical simulation and experimental measurement of SLALOM switching windows for various asymmetries. non-ideal $3 \mathrm{~dB}$ coupler and amplified spontaneous emission.

In conclusion, we presented a time-domain SOA model which incorporates pulse propagation, as well as dynamical and spectral gain effects. Numerical results of the presented model were shown to be in good agreement with experimental pump-probe and SLALOM measurements. The model is thus well-suited to investigate and optimize interferometric switches for a variety of OTDM applications.

${ }^{*}$ Heinrich-Hertz-Institut für Nachrichtentechnik Berlin GmbH, Einsteinufer 37, D-10587, Berlin, Germany; E-mail: hilliger@hhi.de

1. K.S. Jepsen et al., in CLEO'98 Technical Digest (1998), paper CMA1.

2. J.P. Sokoloff $e t$ al., IEEE Photonics Technol. Lett. 5, 787 (1993).

3. M. Eiselt et al., J. Lightwave Technol. 13, 2099 (1995).

4. S. Kindt et al., in OAA'96 Technical Digest (1996), paper FD13.

5. R. Hess et al., IEEE Photonics Technol. Lett. 10, 165 (1998).

\section{CTuW3}

5:00 pm

\section{Bi-directional four wave mixing in} semiconductor amplifiers for mid span spectral inversion: theory and experiment

S. Bischoff, A. Buxens, H.N. Poulsen,

A.T. Clausen, J. Mørk, Center for Communications, Optics and Materials, The Technical University of Denmark, Bldg. 349, DK-2800 Lyngby, Denmark; E-mail: sbi@mic.dtu.dk

Mid Span Spectral inversion (MSSI) is a powerful technique for compensating fiber dispersion in transmission of high-bit rate optical signals. ${ }^{1}$ It was recently demonstrated that aSemiconductor Optical Amplifier (SOA) can be used to perform spectral inversion in both directions simultaneously, ${ }^{2}$ thus allowing to increase the channel capacity of Wavelength Division Multiplexed transmission systems. A schematic drawing of the bi-directional scheme is sketched in Fig. 1. Two signals at $\lambda_{1}$ and $\lambda_{2}$ are launched into a $25 \mathrm{~km}$ long Non Dispersion Shifted Fiber (NDSF). The signals are split at the SOA and injected from each side into a $1200 \mu \mathrm{m}$ long SOA together with a CW pump at $\lambda_{c w}=\left(\lambda_{1}+\lambda_{2}\right) / 2$. The Four Wave Mixing (FWM) thus results in a swapping of the signal wavelengths. The phase conjugated signals are transmitted over additional $25 \mathrm{~km}$ of NDSF after the SOA.

We have developed a large signal model to theoretically assess the performance of a MSSI transmission system. The large signal model

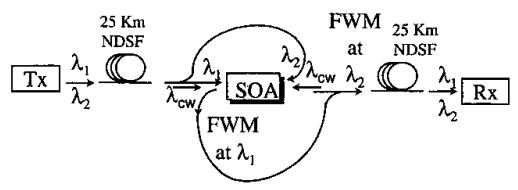

CTuW3 Fig. 1. Schematic of bi-directional technique for MSSI over $50 \mathrm{~km}$ of non dispersion shifted fiber.
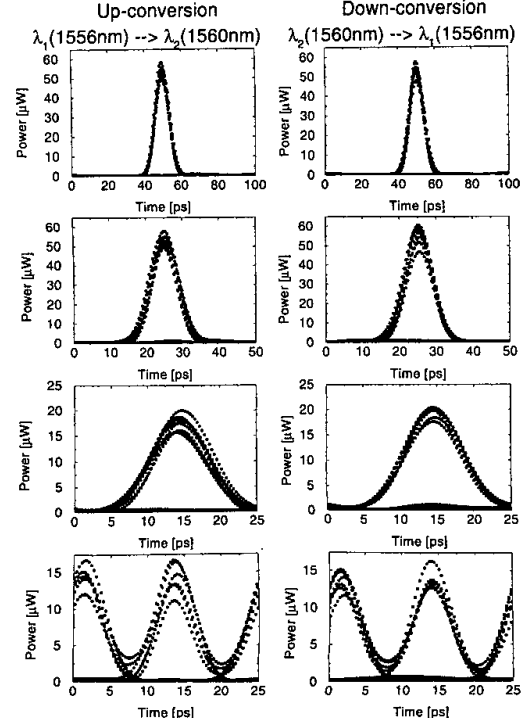

CTuW3 Fig. 2. Calculated eye-diagrams at $10,20,40$ and $80 \mathrm{Gbit} / \mathrm{s}$. The initial pulse Full Width at Half Maximum (FWHM) was 8 ps except for the $80 \mathrm{Gbit} / \mathrm{s}$, where the initial FWHM was 4 ps.

has previously been used to successfully model the fast gain dynamics of SOAs. ${ }^{3}$

In Fig. 2 we display the calculated eye diagrams for the down- and up-converted signals for $10,20,40$ and $80 \mathrm{Gbit} / \mathrm{s}$. The difference in FWM efficiency for up- and down-conversion can be balanced by increasing the CW pump power injected together with the $1556 \mathrm{~nm}$ signal by approximately $0.8-1.2 \mathrm{~dB}$ compared to the $C W$ pump injected together with the $1560 \mathrm{~nm}$ signal. This results in almost equal eye-diagrams for the up- and down-conversion. The signal input powers are kept equal

The best eye-diagrams (small fluctuations in the transmitted pulse peak power) for increasing bit rates are obtained for an increasing small signal gain from $5 \mathrm{~dB}$ at $10 \mathrm{Gbit} / \mathrm{s}$ to $7 \mathrm{~dB}$ at $80 \mathrm{Gbit} / \mathrm{s}$. This corresponds to a decreasing CW pump power from 7 (8) $\mathrm{dBm}$ for down(up-conversion) at $10 \mathrm{Gbit} / \mathrm{s}$ to $5(6) \mathrm{dBm}$ at $80 \mathrm{Gbit} / \mathrm{s}$. The average signal power is found to be around $-7 \mathrm{dBm}$, except for the $20 \mathrm{Gbit} / \mathrm{s}$ signal where the best performance was observed at a signal power of $-4 \mathrm{dBm}$.

The FWM efficiency is found to decrease for lower signal peak power. Accordingly, the FWM performance decreases when the bit rate is doubled while the average power is kept fixed. The simulations indicate good performance at $40 \mathrm{Gbit} / \mathrm{s}$, whereas the eyes start to close at $80 \mathrm{Gbit} / \mathrm{s}$.

Residual facet reflections are found to decrease the system performance, since the reflected signals coincide with the copropagating FWM signal. This results in a significant cross-talk between the two signals. The calculations in Fig. 2 are performed for a reflection coefficient of $10^{-4}$, for higher values the system performance decreases significantly.

Measured eye-diagrams for the bi- 

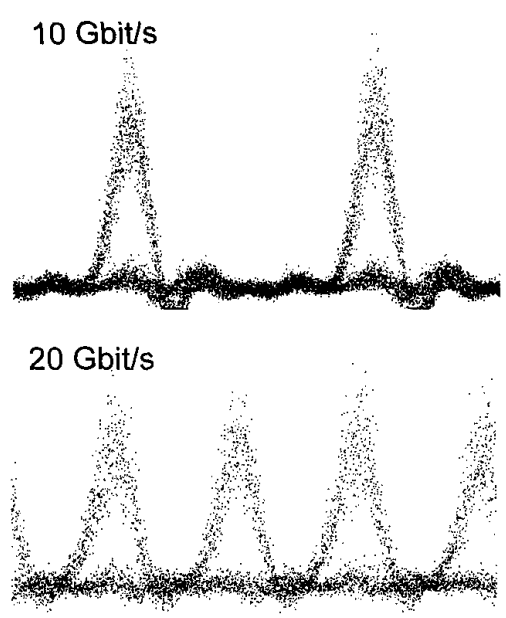

CTuW3 Fig. 3. Experimental measured eyediagrams for a bi-directional transmitted signal at 10 and $20 \mathrm{Gbit} / \mathrm{s}$, respectively.

directional MSSI swapping at 10 and $20 \mathrm{Gbit} / \mathrm{s}$ are shown in Fig. 3. The coupled CW pump power in the experiment was 6 to $7 \mathrm{dBm}$. The coupled signal power was around -6 to $-7 \mathrm{dBm}$. The difference in $\mathrm{CW}$ pump power for equal FWM output power for up- and down-conversion was $2-3 \mathrm{~dB}$. These values are in good agreement with the model predictions.

In conclusion, large signal simulations of a novel scheme of bi-directional FWM are shown to be in good agreement with experiments and identify critical aspects of the system performance.

1. D.D. Marcenac et al., Electron. Lett. 33, 879 (1997).

2. A. Buxens et al., ECOC'98 3, 95 (1998).

3. J. Mark et al., Appl. Phys. Lett. 61, 2281 (1992).

\section{cruW4}

5:15 pm

Demonstration of four wave mixing in an integrated pump laser and semiconductor optical amplifier for midspan spectral inversion dispersion compensation

M.F.C. Stephens, K.A. Williams, R.V. Penty, I.H. White, Department of Electrical and Electronic Engineering, University of Bristol, Queens Building, University Walk, Bristol, United Kingdom BS8 1TR; E-mail: M.F.C.Stephens@bristol.ac.uk

Non-degenerate four wave mixing (NDFWM) has been studied extensively in recent years as both a method for compensating against the dispersion of standard single mode optical fibre via mid-span spectral inversion (MSSI) ${ }^{1}$ and as a transparent wavelength conversion mechanism. NDFWM has been reported in many devices, including semiconductor optical amplifiers (SOAs), distributed feedback (DFB) lasers, nonlinear waveguides and optical fibre itself. ${ }^{2}$ SOAs are promising devices for NDFWM due to their small size, large gain bandwidth and high speed $(>100 \mathrm{~Gb} / \mathrm{s}) .^{3}$ However, an external pump laser and EDFA

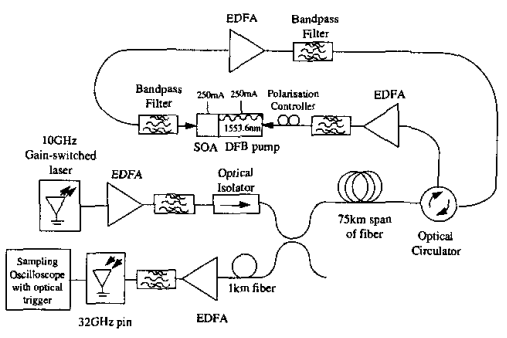

CTuW4 Fig. 1. Schematic of the experimental MSSI arrangement.

a)

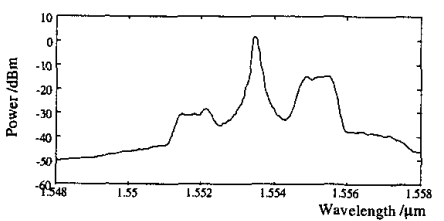

b)

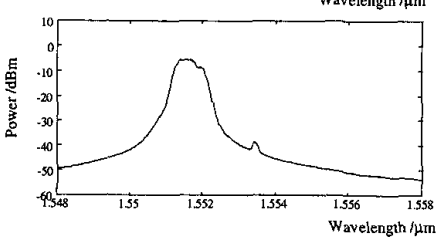

CTuW4 Fig. 2. (a) Spectrum taken directly after the integrated DFB pump/SOA, clearly showing the newly generated phase conjugate at $1552 \mathrm{~nm}$. (b) The phase conjugate signal after filtering and amplification.

are required which adds both cost and complexity to the system. Recently, an integrated DFB laser and SOA has been reported for wavelength conversion under static conditions. ${ }^{3}$ Here, for the first time we believe, the use of a similar device for dynamic MSSI dispersion compensation is demonstrated.

The experimental arrangement is depicted in Fig. 1.

A $10 \mathrm{GHz}$ train of 18 ps pulses is generated by gain-switching a $1555.2 \mathrm{~nm}$ DFB laser. These pulses are amplified by an EDFA and injected into a $75 \mathrm{~km}$ span of standard fibre. The output of the span is passed via an optical circulator into another EDFA and filter before injection into the DFB laser section of the phase conjugator. A polarisation controller is used to match the polarisation of the incoming signal to that of the DFB pump beam. The DFB pump wavelength is at $1553.6 \mathrm{~nm}$ and has a linewidth of $\sim 2 \mathrm{MHz}$ when both it and the SOA are biased at $250 \mathrm{~mA}$. The newly generated phase conjugate signal at $1552 \mathrm{~nm}$ is filtered to remove the pump and original signal before being amplified, filtered again and transmitted back over the span. The received signal is analysed after traversing an additional $1 \mathrm{~km}$ of standard fibre, which compensates for the dispersion induced by the wavelength difference on the two spans. The pulses are examined using a $32 \mathrm{GHz}$ photodiode and $50 \mathrm{GHz}$ sampling oscilloscope.

The optical spectra produced from the output of the phase conjugator are shown in Fig. 2 before and after filtering. The average injected signal power to the phase conjugator is +3.5

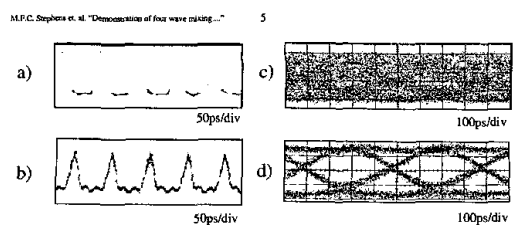

CTuW4 Fig. 3. (a) $10 \mathrm{GHz} 18$ ps input pulses at $1555.2 \mathrm{~nm}$. (b) Received phase conjugate pulse at $1552 \mathrm{~nm}$ after $151 \mathrm{~km}$ of standard fibre. (c) 2.5 $\mathrm{Gb} / \mathrm{s}$ eye with no MSSI at $1555.6 \mathrm{~nm}$. (d) Phase conjugate $2.5 \mathrm{~Gb} / \mathrm{s}$ eye after $151 \mathrm{~km}$.

$\mathrm{dBm}$. After filtering it can be seen that the residual peak pump level is over $30 \mathrm{~dB}$ lower than the phase conjugate.

The back to back and final received pulses are shown in Figs. 3(a), 3(b). It can be seen that there is some degradation of the signal after the $150 \mathrm{~km}$ span. In addition, a highly chirped laser is modulated at $2.5 \mathrm{~Gb} / \mathrm{s}$ and transmitted over the system. The received eye is shown in [Fig. 3(d)] with no significant degradation. Without MSSI, the same eye diagram is completely closed [Fig. 3(c)]

In conclusion, for the first time, an integrated DFB/SOA laser has been shown to operate as an MSSI dispersion compensator via NDFWM with a $10 \mathrm{GHz}$ pulse train and $2.5 \mathrm{~Gb} / \mathrm{s}$ data. Although the former does show some degradation, it is believed that further optimisation of the device (such as reduced DFB linewidth) will lead to far superior performance. A full bit error rate analysis and results at $10 \mathrm{~Gb} / \mathrm{s}$ will be presented at the conference.

1. D.D. Marcenac, D. Nesset, A.E. Kelly, M Brierley, A.D. Ellis, D.G. Moodie, C.W. Ford, Electronics Letters, 1997, 33, No. 10, pp. $879-880$

2. S.J.B. Yoo, IEEE Journal of Lightwave Technology, 1996, 14, No. 6, pp. 955-966.

3. A.E. Kelly, A.D. Ellis, D. Nesset, R. Kashyap, D.G. Moodie, Electronics Letters, 34, No. 20, 1st October 1998, pp. 1955-1956.

4. T. Simoyama, H. Kuwatsuka, B.E. Little, M. Matsuda, Y. Kotaki and H. Ishikawa, 1998 IEEE 16th International Semiconductor Laser Conference, Nara, Japan, paper PD-7, pp. 15-16.

\section{CTuW5}

5:30 pm

Saturation properties of four-wave mixing between short optical pulses in semiconductor optical amplifiers

J. Mørk, A. Mecozzi, ${ }^{*}$ S. Diez, ${ }^{* *}$ Center for Communications, Optics and Materials, The Technical University of Denmark, Bldg. 349, DK-2800 Lyngby, Denmark; E-mail: jm@com.dtu.dk

Four-wave mixing (FWM) between short optical pulses in a semiconductor optical amplifier (SOA) is of considerable interest for performing high-speed optical de-multiplexing or optical sampling. ${ }^{1-3}$ The large gain of the SOA makes efficient FWM over detunings of several nanometers possible. Since FWM relies on physical processes (like carrier density modulation and ultrafast intraband carrier dynamics 